\title{
Deus sem Ser e Ser divino
}

\begin{abstract}
Rubens Garcia Nunes Sobrinho*
Resumo: Este artigo tem como escopo cotejar a tese da irredutibilidade da teologia de Jean-Luc Marion com a ontologia platônica. No ensaio "Deus sem Ser", Jean Luc Marion postula a absoluta liberdade e transcendência de Deus em relação todas as determinações ontológicas, incluindo a condição primeira que torna todas as demais determinações possíveis: o fato do Ser. As implicações da teoria das imagens e da distinção entre ídolo e ícone no estatuto do divino em Platão colocam em questão a tese da irredutibilidade teológica. Tendo em vista uma contraposição entre a teologia irredutível ao conceito de Ser de Marion e a ontologia platônica, o artigo examina a distinção semântica entre ídolo e ícone e a conexão que serve de base à "destituição metafísica". O artigo revê a ontologia platônica mediante a proposta epistemológica de um "pensar por imagens" como mediação entre o divino e o humano.
\end{abstract}

Palavras-chave: Ídolo. Ícone. Ser.

\section{God without Being and divine Being}

\begin{abstract}
This article aims to cross-check the irreducibility thesis of Jean-Luc Marion's theology with the platonic ontology. In his essay "God without Being" Jean-Luc Marion postulates the absolute freedom and God's transcendence in relation to all the ontological determinations, including the primary condition that makes all the other possible determinations the "fact of the Being". The implications of the Theory of Images and the distinction between "idol" and "icon" in the role of the divine in Plato call into question the theological irreducibility thesis. In view of a contrast between the irreducible theology to the concept of Being in Marion and the platonic ontology, the article examines the semantic dis-
\end{abstract}

* Doutor em Filosofia pela Universidade Federal de Minas Gerais (UFMG). Professor do Instituto de Filosofia da Universidade Federal de Uberlândia (UFU). Responsável pelo Núcleo de Estudos de Filosofia Antiga (NEFAH) do IFILO/ UFU.E-mail: rgns11@gmail.com. 
tinction between "idol" and "icon" and the connection that forms the basis of the "metaphysical destitution". The article reviews the platonic ontology through the epistemological proposal of a "thinking through images" as a mediation between the divine and the human.

Keywords: Idol. Icon. Being.

\section{Dieu sans Être et Être divine}

Résumé: Cet article vise à comparer la thèse de l'irréductibilité de la théologie de Jean-Luc Marion avec l'ontologie platonicienne. Dans son essai «Dieu sans être» Jean-Luc Marion postule la liberté absolue et la transcendance de Dieu par rapport à toutes les déterminations ontologiques, y compris la condition première qui fait de toutes les autres déterminations possibles le «fait de l'être». Les implications de la théorie des images et la distinction entre «idole» et «icône» dans le rôle du divin chez Platon posent en question la thèse de l'irréductibilité théologique. Compte tenu d'une opposition entre la théologie irréductible au concept de l'Etre de Marion et l'ontologie platonicienne, l'article examine la distinction sémantique entre idole et icône et la connexion qui sous-tend le «destituition métaphysique ». L'article passe en revue l'ontologie platonique à travers la proposition épistémologique d'une «pensée par images», comme une médiation entre le divin et l'humain.

Mots-clés: Idole. Icône. Être.

\section{Introdução}

Em um trabalho já clássico, Deus sem ser, J. L. Marion coloca as categorias e os limites do pensar em questão, particularmente, a Metafísica entendida como a teoria do ser que fundamenta todos os seres. Não se trata, segundo ele, de colocar em questão a existência de Deus, mas de se questionar a pretensão de se pensar Deus como o Ser que determina e define todos os seres. A determinação metafísica de Deus é posta em cheque e Marion explicita a necessidade de se identificar uma modalidade não metafísica de pensamento de Deus e enquadrá-la no que chama de "destituição metafísica". 
O âmbito da reflexão da destituição metafísica se opõe à desconstrução empreendida pelos pós-modernos, particularmente Heidegger, à concepção aristotélica de Deus como o primeiro motor imóvel e fundamento último de todos os seres e à concepção tomista de Deus como Causa Sui. Para se pensar Deus fora do horizonte da metafísica e superá-la, é preciso adotar a teologia como nova modalidade do pensar. Para tanto, Marion explicita a diferença entre ídolo e ícone de modo a circunscrever e identificar a crítica pós-moderna da metafísica como idolatria.

A irredutibilidade da teologia implica um excesso que se sobrepõe a todo conceito e à própria faculdade racional de fabricar conceitos. A superação da aprioridade dos conceitos encontra operacionalidade numa atitude de distanciamento. A metáfora espacial da distância marca a impossibilidade de apreensão conceitual de Deus e estabelece a diferença radical entre Deus e o humano.

O objetivo deste estudo se restringe em cotejar a teologia de Marion com uma leitura recente da ontologia platônica a partir da epistemologia e estatuto das imagens. Odetalhamento das múltiplas implicações do ambicioso projeto de superação da metafísica proposto por Marion vai muito além do foco deste trabalho. Para justificar a conciliação entre uma teologia irredutível ao conceito de Ser e a ontologia platônica, me limitarei a esboçar os seguintes pontos: (1) um exame das noções de ídolo e ícone empreendido por Marion e sua conexão com a destituição metafísica; (2) confrontar este exame com o estatuto das imagens na filosofia de Platão e (3) apontar uma redefinição da ontologia platônica de modo a propor um "pensar por imagens" como mediação entre o divino e o humano. É o que passarei a fazer em seguida.

\section{1. Ícone e ídolo, na teologia de Marion}

A abordagem da noção de ídolo só pode ser feita em relação ao seu contraponto: o ícone. Eidōlon pressupõe o esplendor grego do visível, de cuja policromia emerge a polissemia do divino, enquanto o eikon, concentra o Único Um. 
Tanto ídolo como o ícone indicam somente seres particularizados, ou seja, modalidades de ser para os seres. Como signo do divino, o ídolo encena o suporte de um espectro visível. Variações no modo de visibilidade correspondem a modos de apreensão e de recepção variáveis do divino.

Em sua etimologia, o ídolo implica aquilo que se apresenta ao olhar e, como tal, é conhecido enquanto imagem. A raiz de عî́ $\omega$ é a mesma de oî̃ $\alpha$. Por conseguinte, o ídolo se manifesta ao olhar simultaneamente como imagem e algo reconhecido como tal: representação que prende o olhar.

$\mathrm{O}$ efeito produzido pelo ídolo consiste na fascinação hipnótica que domina o olhar mediante a satisfação do seu preenchimento. O ídolo congela e ofusca o olhar no domínio da visibilidade e o cativa instaurando uma dependência mútua que se exaure na própria visibilidade.

É o olhar que faz o ídolo, cuja única função consiste em ser visto, fixado. Como suporte do visível, o ídolo não é um fim em si mesmo, mas sempre aponta para uma função que remete à anterioridade e primazia do olhar que o visa.

Por outro lado, diante do ídolo, a primeira intenção do olhar é a remissão ao divino. Essa primeira intenção do olhar, que penetra o campo do visível, é saciada na fixação que interrompe o fluxo do espetáculo. O ídolo sequestra o olhar da visibilidade ao se apresentar como o primeiro visível, que não pode mais ser penetrado pelo o olhar e o reenvia, como espelho, para si mesmo.

Diferentemente do retrato, o ídolo espelha a imagem do próprio olhar e daquilo que constitui o seu escopo e a sua visada. $\mathrm{O}$ esplendor do ídolo apenas reflete o brilho do olhar que descansa em seu ponto de parada. A sua função espetacular ofusca e satura o olhar com o visível, congelando-o. Esta espécie de saciedade do olhar perscrutador mascara o seu próprio reflexo e faz do ídolo um espelho invisível.

Esta outra função especular do ídolo exaure a visada do olhar que nele busca o fim inexorável de seu repouso. Finalidade estática do olhar, o ídolo se desqualifica frente à revelação divina porque sua opacidade não admite nenhum além e, sobretudo, não enseja o "invisível”. Tal função 
especular reduz o divino à dimensão visível própria ao olhar que o fixa e contempla. O templo é a medida idolátrica para a manifestação divina que cada olhar é capaz de suportar. $\mathrm{O}$ ídolo circunscreve o divino à medida do olhar humano e seu único referente é a experiência da presentificação de um modo humano de ver o divino.

Se o ídolo se apresenta em um espetáculo estético, ao mesmo tempo em que mascara seu papel de espelho invisível do olhar, a maior idolatria ocorre no âmbito do ídolo conceitual. $\mathrm{O}$ conceito consigna e subsume a um signo a própria capacidade humana de abstração de traços de comuns a uma multiplicidade. Como afirma Marion, quando um pensamento filosófico expressa um conceito daquilo que ele nomeia como "Deus", este conceito funciona exatamente como um ídolo. (MARION, 2012, p. 16).

$\mathrm{O}$ conceito atrai o pensamento para um ponto fixo, mas oculta seu papel de espelho invisível e onde o pensamento espera encontrar seu alvo acaba por encontrar-se a si mesmo, congelado em um conceito idólatra de Deus. A medida do conceito não provém de Deus, mas tão somente da visada do intelecto que julga a si mesmo.

\section{O ícone e o invisível}

Ao contrário do ídolo, o ícone não deriva da visão, mas engendra uma a partir de uma similitude. Eî́ $\omega$ significa parecer, assemelhar e, por isso, o ícone não aparece ao olhar, mas obriga o olhar a perscrutar no visível uma similitude invisível. No ícone, o invisível se inscreve no visível porque este procede daquele. Assim, o invisível instaura-se no visível de modo que seja inferido a partir do visível.

O ícone induz o olhar a ultrapassar a si mesmo através do visível e o convida a inferir o invisível num movimento infinito. A divindade invisível não se faz visível a não ser em termos de ov̉oí $\alpha$, do inteligível inferido a partir do visível. O ícone possui um estatuto teológico porque a oủoía não se

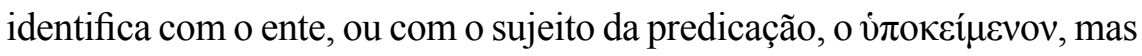
se faz inteligível como hypostasis, como inscrição subjacente da intenção. 


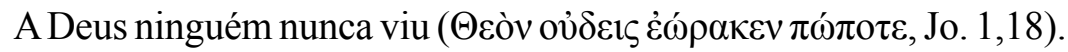
Ele se revelou. Por isso, Marion lembra que Cristo é o ícone do Deus

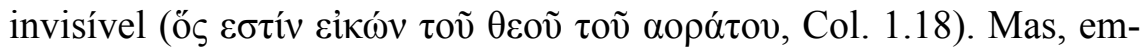
bora Marion não tenha prosseguido no contexto do passo, a causalidade intencional criadora se infere a si mesma deste ícone do Deus invisível

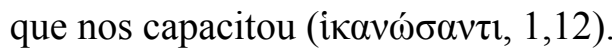

No ícone, visível e invisível, coexistem na distância do aprofundamento infinito mediante a intenção do invisível se desdobrar no visível pela graça. O único meio conceitual inteligível para o ícone é a desmedida do infinito. Por essa razão, Descartes identifica a ideia de Deus com a ideia de Infinito. "Para ter uma ideia verdadeira do infinito ele não se deve de nenhum modo ser compreendido, uma vez que a própria incompreensibilidade está contida na razão formal do Infinito" (Quintas Respostas, VII, 368, 2-4).

A hermenêutica do ícone implica que o invisível só se inscreve na visibilidade mediante a intenção. Nenhum conceito pode subsumir a desmedida do infinito e toda pretensão ao conhecimento conceitual absoluto denuncia o domínio da idolatria.

Por outro lado, a abolição da diferença ontológica implica a impossibilidade absoluta de se pensar. Todavia, justamente a incapacidade de se pensar - quando se trata de pensar Deus - não indica, segundo Marion, nenhuma absurdidade, uma vez que a diferença ontológica reduz a desmedida infinita de Deus ao métron humano. O impasse sugere que a impossibilidade de se pensar que decorre da abolição da diferença ontológica representa tão somente a impossibilidade de se pensar Deus enquanto Ser. Os sistemas que buscam fazê-lo constituem o último dos ídolos.

Como se poderia pensar ou falar de Deus fora do conceito? A resposta inequívoca é dada pela revelação: Deus é Ágape aquele que permanece

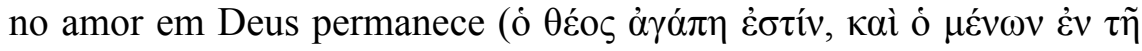
$\dot{\alpha} \gamma \alpha \dot{\alpha} \pi \eta \dot{\varepsilon} v \tau \tilde{\omega} \theta \varepsilon \tilde{\omega} \mu \dot{\varepsilon} v \varepsilon 11$ Jo. 4:8). Por que o amor permite que se pense Deus sem reduzi-lo à diferença ontológica? $\mathrm{O}$ amor transpõe a questão 
do Ser de Deus, ou de quem é Deus, para a questão: “o que é Deus" ou o que é o Amor?

O Amor não se furta às condições de possibilidade do conceito. Deus é não por causa do Ser, mas é incondicionalmente, logo é o amor infinito incondicional. O Amor não está nem no âmbito do limitado nem do indefinido indiferenciado. O amor é o infinito. Só amamos Deus porque ele nos amou primeiro e para responder este amor é necessária e suficiente apenas a vontade, que pode receber ou recusar. Fora do domínio conceitual, Deus ágape não pode ser aprendido, logo não pode ser idolatrado. O Amor de Deus não é uma posse: é um dom gratuito que exclui o ídolo.

\section{3. Ídolo e ícone em Platão}

No corpus platônico, os fenômenos se exprimem por uma gama de termos como: phainómenon, eídōon, eikōn, phántasma, mímēma, homoiōma e outras (SEKIMURA, 2009, p. 22 ss.). Mas, Platão hierarquiza o estatuto das imagens. Há uma clara distinção entre eídōlon, phántasma e eikōn. Há imagens que são determinantes no processo do conhecimento, há imagens cujas relações são empobrecidas em relação ao modelo original e há imagens ilusórias que impedem a apreensão da realidade. A distinção entre eídōlon e eikōn é argutamente exposta por Suzanne Saïd:

Se as duas palavras são formadas a partir de uma mesma raiz ,,wei"-, somente eídōlon por sua origem emerge da esfera do visível, pois é formada sobre um tema ,, weid"e - que exprime a idéia de ver (este tema que deu ao latim ,,video", se encontra em grego, no verbo ,idein" „, vere e no substantivo eidos que se aplica inicialmente à aparência visível). O eikōn, do mesmo modo que os verbos eisko ou eikazdo ,, assimilar" ou o adjetivo eikelos ,, semelhante ${ }^{\text {ee }}$, se vincula a um tema ,weike- que indica uma relação de adequação ou de conveniência (SAÏD, 1987, p. 310). 
O termo eídōlon se forma sobre o mesmo tema que origina Eîdos e Idéa, designativos da realidade inteligível e de sua ação causal determinante. A relação entre as imagens e o inteligível invisível é constitutiva. Nesse sentido, como afirma Saïd, existe "entre o eídolon e seu modelo uma identidade de superficie e de significante, enquanto a relação entre o eikōn e o que ele representa se situa no nível da estrutura profunda do significado" (SAÏD, 1987, p. 310).

O eídōlon está para o eikōn, assim como a cópia da aparência sensível está para a transposição da essência. O eídolon é inerente ao olhar, é o alvo e o ponto de encontro entre o olhar e a silhueta que nada informa acerca das determinações do modelo. Ele é valorizado ou desvalorizado pela relatividade do olhar e sua manifestação, ao modo das imagens dos deuses, implica simultaneamente a presença e a ausência. Sua marca é a do empobrecimento e do afastamento em relação ao modelo original.

Em Platão, eídōlon e phántasma capturam o espectador que ignora o seu caráter de simulacro e é incapaz de discernir a essência de sua aparência enganadora e ilusória. A aparência visual pressupõe tanto uma ação produtora como uma ação receptora. Um simulacro é uma aparência que não remete para a inteligência de um modelo.

A diferença entre o simulacro e o eikōn redunda na questão da simetria. A simetria de um eídōlon é apenas a medida ótica que cativa o olhar, ao passo que a simetria do eikōn é a simetria real das relações proporcionais. Enquanto o eídōlon visível é assimilado à pura aparência manifesta, o eikōn manifesta a relação de um registro de realidade visível com um paradigma inevidente.

O eikōn, por outro lado, carrega em seu bojo a remissão plurívoca a planos diversos. Ele pode ser o ponto de partida para o conhecimento de relações e determinações sensíveis ou pode remeter à realidade inteligível. No eikōn, a inteligência se vale do olhar para ultrapassar a imagem e, mediante a transposição e a homologação de suas relações internas, "saturar-se" gradativamente do inteligível e do invisível no foco das relações somente pensáveis. O visível remete para o inteligível não tanto porque participa deste, mas porque é conquistado e determinado pelo 
inteligível. As imagens icônicas constituem o esforço infinito de pensar filosoficamente o invisível, a morte, a alma e os referenciais imóveis exigidos para a compreensão de um mundo caótico.

Por isso, a inteligência se vale de imagens icônicas na tentativa de compreender o invisível e operar a passagem da percepção para a inteligibilidade. Não é por acaso que os mitos filosóficos estão na esfera da crença que possui a pretensão de ser o lógos mais verdadeiro: suas imagens são um convite para a inquirição da significação profunda subjacente aos fenômenos cambiantes caóticos.

As imagens míticas convocam a inteligência e o olhar a jamais se fixarem naquilo que é visto e manifesto e ascenderem em direção ao invisível, ao inteligível, até que a luz do relâmpago, subitamente, se acenda pelo movimento psíquico. O mito filosófico é um "pensar por imagens" e é, também, a única modalidade de pensar que não se fixa no visível, mas que convoca para a significação mais profunda, oculta na maior profundeza do oceano do belo.

\section{A ontologia platônica como transcendência do Ser}

No diálogo Timeu, para discorrer sobre a criação do cosmo, Platão estabelece a distinção ontológica:

Temos primeiro que começar por fazer a seguinte distinção: o que é que é sempre sem jamais devir, e o que é que devém sempre, sem jamais ser? É evidente que pode ser apreendido pelo pensamento e ser objeto de explicação o que permanece sempre idêntico. Ao invés, o segundo pode ser objeto da opinião ao termo de uma percepção rebelde a toda explicação racional, que que nasce e se corrompe, o que não é realmente jamais. Além disso, tudo o que é engendrado é necessariamente engendrado sob o efeito de uma causa, pois, sem a intervenção de uma causa, nada pode ser engendrado (Timeu 27.d-28.a). ${ }^{1}$

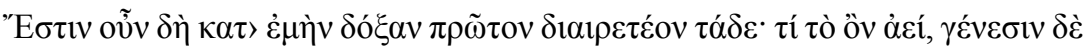

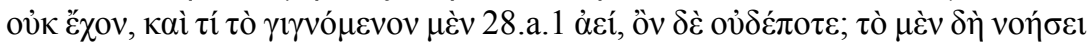


O discurso que fala sobre as origens cosmológicas não é um discurso conceitual, mas um discurso imagético. Todo o Timeu é um mito

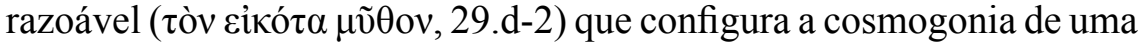
cosmologia racional. A distinção ontológica entre o devir e o Ser imutável pressupõe a ação criadora de uma divindade limitada com características psíquicas antropomórficas. O Demiurgo se extasia com o Belo e a ordem, mas é limitado e incapaz de suprimir a desordem intrínseca ao meio espacial, realidade pré-cósmica que garante a inscrição da ordem na desordem.

O discurso sobre a criação cosmológica opera a redução do divino aos limites do pensamento humano. Todavia, o encontro efetivo do Deus é muito difícil e impossível de ser expresso linguisticamente: "Encontrar o compositor e pai do cosmo exige um esforço e, quando encontrado, é impossível falar dele a todo mundo" (Timeu. 29.a) ${ }^{2}$. Toda a atividade demiúrgica criadora, que visa a reprodução estética do belo, é movida por um amor à ordem e à verdade do paradigma eterno e infinito.

No Fédon, Platão postula a divisão fundamental entre as formas de todos os seres que existem: de um lado a visível e, de outro, a invisível ${ }^{3}$. O plano cambiante dos fenômenos constitui a realidade visível, passível de ser apreendida pela percepção, e em cuja multiplicidade cada ser particular pode ser designado pelo mesmo nome, segundo suas determinações essenciais próprias (Fédon, 78.d-e). Por outro lado, a Essência - passível de ser apreendida somente pelos raciocínios e investigada pelos discursos racionais, é imutável, constante, eterna, pura, sem mistura, una e divina (Fédon, 78.d).

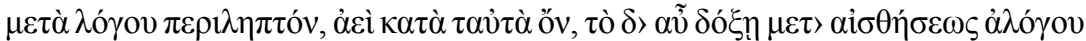

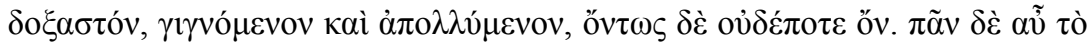

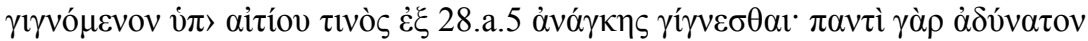

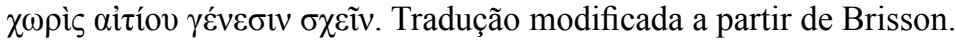

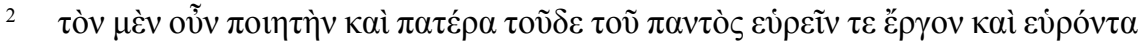

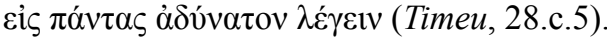

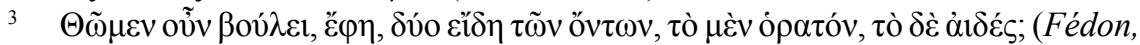
79.a.6-7) 
O contato da alma com a realidade que existe em si mesma, o modo de ser divino que causa todas as demais realidades, configura uma experiência da qual resulta um estado psíquico:

Quando ao contrário, é a alma mesma, somente por si mesma, que conduz seu exame e se enlaça ao que é puro e que existe sempre, que é imortal e sempre semelhante a si? E como ela é aparentada a esta 'maneira de ser', ela permanece sempre em sua companhia, cada vez em que, ela mesma concentrando-se em si mesma, isto se torna possível. A sua errância termina: na proximidade destes Seres, em si mesma, ela permanece semelhante a si mesma, já que ela está em contato com os seres. Este estado (páthēma) da alma é o que se chama phrónesis ${ }^{4}$.

A phrónesis ${ }^{5}$ demarca não uma faculdade psíquica, mas uma condição, ou estado, pelo qual a alma tem contato com a realidade divina cuja inteligibilidade emerge de um esforço e enseja uma experiência. A realidade divina está para além da manifestação visível dos fenômenos. Ela afeta o estado da alma na medida em que esta estabelece uma relação, ou parentesco, com o divino.

A phrónesis resulta do contato da inteligência com o inteligível. Pela phrónesis, a alma satura-se do divino e se torna consonante a ele. Ela é o estado psíquico que possibilita a apreensão do Belo e do Bem. Mas, ao contrário do Belo, a phrónesis não possui o privilégio de manifestarse no esplendor das imagens e suscitar o desejo através delas (Fedro, 250.d.5). Alvo de todos os esforços filosóficos, este estado de alma é

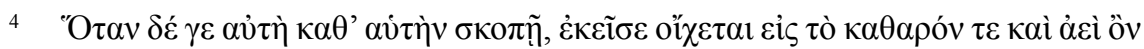

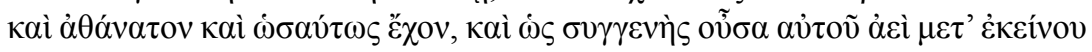

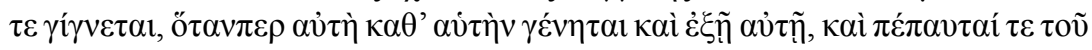

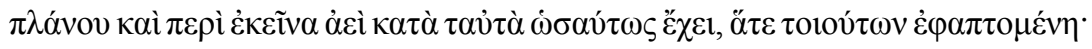

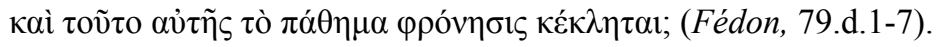

5 Para uma discussão ampla acerca do significado de phrónesis em Platão, ver: Dixsaut, M. Platon et La question de la pensée, 2000, e Durant, M. Trois lectures du Phédon de Platon, 2006. 
aquilo pelo qual os filósofos desejam (epithymoûmém) e se declaram amantes: a phrónesis ${ }^{6}$.

Por isso, a phrónesis, ao mesmo tempo em que é o valor humano mais elevado, inscreve valor em todas as ações, porque pressupõe a comunhão com o divino. Objeto do 'apetite' filosófico, a phrónesis representa o amor pelo divino. Se, como afirma Platão, "tudo para o homem depende da alma", no que concerne "à alma mesma, tudo depende da phrónesis" (Ménon, 88.d-89.e). Por conseguinte, tudo o que concerne ao humano depende da comunhão (koinonía) com o divino.

Em Platão, o Belo opera a instauração de uma relação afetiva que implica a experiência de ser afetado. O Belo possui um estatuto causal na medida em que engendra uma aspiração, um desejo que impele um movimento rumo ao seu alvo. Ponto de parada do desejo, o Belo em si mesmo não pode ser jamais apreendido numa posse, pois está para além da realidade visível. Por isso, o Belo só pode corresponder a um amor que aspira à imortalidade e ao infinito.

Somente mediante o exame discursivo se pode operar a unificação da multiplicidade indeterminada de coisas belas. Esta operação unificadora pressupõe a potência da alma:

Nós afirmamos que há um grande número de coisas belas e de coisas boas, e assim em cada caso, nós as distinguimos pelo lógos. (...) $\mathrm{E}$ quanto ao belo em si mesmo, assim como em todas as realidades que então estabelecemos como múltiplas, nós o estabelecemos desta vez, ao contrário, segundo uma ideia única de cada uma derivando de uma ideia única, e nomeamos o que foi estabelecido "aquilo que é"7.

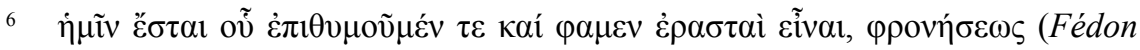
66.e.2)

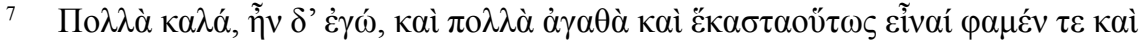

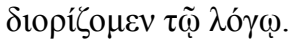

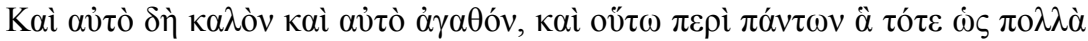

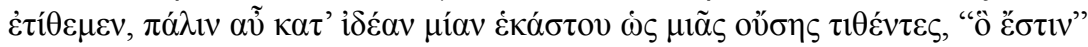

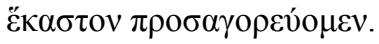


A inteligência possui a potência de unificar em uma ideia única as determinações essenciais que conferem a existência e as propriedades de uma multiplicidade designadas pelo mesmo nome. Dentre todas as ideias, como operações unificadoras da alma, a ideia do bem é o maior ensino e é por ela que as coisas justas e as outras se tornam úteis e proveitosas ${ }^{8}$.

Por outro lado, a Filosofia é um amor pela verdade e pelo Bem. No processo do conhecimento, a inteligência se vale de imagens para estabelecer hipóteses e ascender a relações somente pensáveis. Nas ciências, a alma se serve de hipóteses como ícones dos princípios que lhes servem de paradigmas. Mas a modalidade mais elevada de inteligibilidade não emprega hipóteses ou mesmo o discurso das ciências. Em vez disso, a inteligência usa a potência discursiva como meio de apreensão do princípio último não-hipotético:

Compreende, então, que para a segunda seção do inteligível, eu quero designar aquilo a que o discurso se liga pela potência dialética, considerando hipóteses não como princípios, mas realmente como hipóteses, a saber, como bases para tomar seu élan de modo a chegar até ao não-hipotético, ao princípio de tudo; e sendo ligada a este princípio, ele chega às consequências derivando deste princípio e descendo à conclusão, sem fazer de todo uso de nenhum elemento da percepção; é pelas formas em si mesmas, passando através delas para atingir somente a elas mesmas, que ele encontra sua conclusão nas formas. ${ }^{9}$

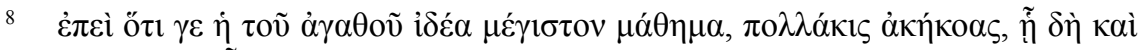

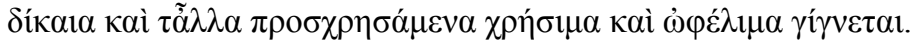

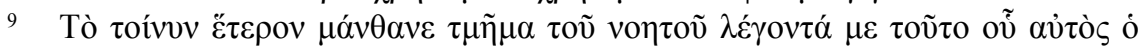

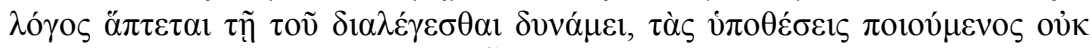

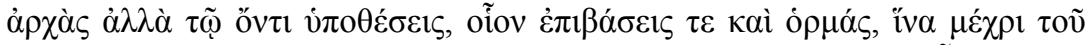

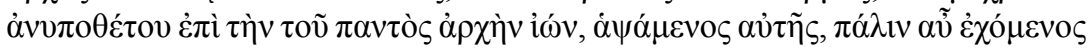

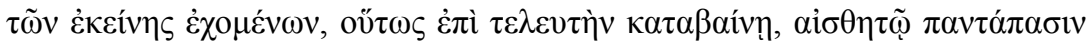

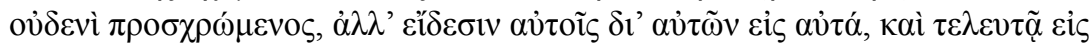

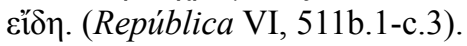


A alma fricciona as imagens do Inteligível, a saber: a linguagem, as definições, os ícones, as visões e as sensações - até que, subitamente, emerja a luz da sabedoria e da inteligência ${ }^{10}$. Não obstante, o mais alto objeto de ciência ( $\tau$ ò $\mu \varepsilon ́ \gamma \imath \sigma \tau o v \mu \alpha ́ \theta \eta \mu \alpha$ ) é a ideia do Bem. A investigação platônica sobre o Bem transcende a capacidade racional da compreensão, a capacidade de abarcar o Bem no âmbito da inteligência humana.

O Bem não é o bem em nós ${ }^{11}$, o bem pluralizado nos seres, nem uma essência particular, mas algo que está para além da essência em antiguidade e potência ${ }^{12}$. Não sendo essência, o Bem tampouco é o Ser dos seres, ainda que os seres derivem sua existência e sua essência dele. O Bem se mostra para além da verdade e da ciência - assim como o Sol se mostra além dos órgãos sensitivos - especialmente a vista e as imagens que constituem o seu alvo.

Essas assunções implicam que o bem que se pluraliza nos seres não é idêntico à ciência e ao pensamento - pois nos outros domínios o bem absoluto não é idêntico à ciência. Ele se faz mostrar estando além da realidade, como o Sol mostra-se a si mesmo além da luz. Segue-se que o Bem não admite em si mesmo a noção de essência.

Aquilo que está acima da realidade não pode nem ser o real (o que é determinado essencialmente pela ousía), nem ser realmente. Se ele existe e não é a essência do real, então deveria ser o não-ser, o que é impossível.

Platão diz que o "ser não real" (não determinado essencialmente) vem depois do "ser real" (determinado essencialmente). Por outro lado

10 Carta VII 344.b.10.

11 Em seu comentário à República, Proclus $(1070$, p. 85) estabelece a distinção entre o "bem em nós" e o Bem no sentido absoluto: (...) le Bien est évidemment montré au-delà de l'intellect et de la Science, comme le soleil est au-delà des organes sensitifs et, parmi ces organes, spécialement de la vue. Et par consequente, em vertu de cette assomption, il apparaît que le bien em nous n'est pas non plus identique à la Science et à la pensée, s'il est vrai eu, dans les autres domaines non plus, le Bien au sens absolu n'est pas identique à la Science.

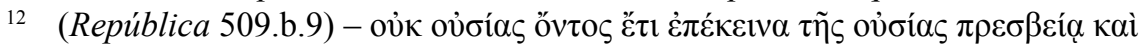

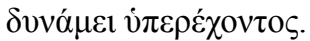


o Bem não é o ser determinado essencialmente, porque ele engendra a realidade e todo ser real participa necessariamente da ousía. O Bem se mostra para além da essência.

Se (1) o ser real existe a partir do Bem e (2) o Bem é fonte da realidade (ovбí $\alpha$ ) - que é superior à essência assim como a fonte da luz é mais elevada ao que é visível graças à luz - então o Bem é superior à essência. Isso implica que o Bem é superior às determinações essenciais que condicionam a existência de todos os seres.

Por outro lado, sendo o Bem anterior e superior à essência, é igualmente a fonte primordial do amor que se faz mostrar na determinação do Belo. A aspiração filosófica pelo Ser, pela verdade e pelo Belo só existe pela instauração do bem em nós, efetivada pelo amor primordial do Bem - o qual está para além da fenomenologia do ser e da verdade.

\section{Conclusão}

A distinção ontológica de Platão postula a separação de uma realidade inteligível divina (ovбía) do plano dos fenômenos do devir. A realidade inteligível causa e determina o plano dos fenômenos mediante as Formas inteligíveis ( $(\tilde{i} \delta \eta)$, que discriminam todas as propriedades dos seres. Os seres são "conquistados" pelas Formas - em uma ação estruturadora inteligente - de onde deriva a inscrição de ordem e beleza na desordem.

Os seres participam da realidade inteligível divina através da ação estruturadora e das determinações múltiplas inscritas pelas Formas. Esta ação suscita a apreensão pela inteligência da causalidade, da estabilidade, da unidade e simetria no plano da multiplicidade. A Ideia indica a inteligibilidade passível de ser apreendida racionalmente pela inteligência humana.

A distinção ontológica de Platão implica a distinção semântica entre

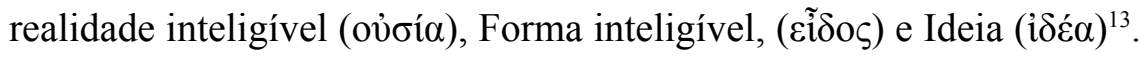

13 Dixsaut (2000); Bernabé (2013). 
Mas a distinção ontológica platônica não implica o Ser dos seres, ou o Bem como gênero supremo, ou como causa sui. Nesse sentido, deverse-ia começar por retificar um equívoco: em vez da inquirição acerca de "quem é Deus", a questão essencial aponta para "o que é Deus".

A resposta inequívoca deve ser o marco zero da teologia: Deus é infinito ágape. A filosofia platônica, a partir disso, pode constituir um ícone solidário à teologia de Marion, de modo que o Deus sem ser possa ser pensado a partir da imagem icônica do Ser divino platônico.

\section{Referências}

BERNABÉ, A. “عĩdo en los filósofos présocráticos”, In: ROMERO, G. F.; SERRANO, P. G.; MUÑOZ, F. H.; SÁENZ, O. O. (Ed.). eĩoo en los filósofos présocráticos, TH $\Gamma \Lambda \mathrm{O} \Sigma \Sigma \mathrm{A}$ MOY E $\Delta \Omega \Sigma \mathrm{AN}$ E $\Lambda \Lambda H N I K H$, Berlin: Verlag, p. 91-104, 2013.

DIXSAUT, M. Platon et la question de la pensée. Paris: Vrin, 2000. . Le naturel philosophe, Paris: Vrin, 2001. . Platon: le désir de comprendre, Paris: Vrin, 2003. . Études sur la république de Platon, Paris: Vrin, 2005. . Platon et la question de l'âme. Paris: Vrin, 2013.

DURANT, M. Trois lectures du Phédon de Platon, Paris: L'Harmattan, 2006.

GOLDSCHMIDT, V. La religion de Platon, Paris: P.U.F., 1949.

MARION J. L. Fragments sur l'idole et l'icône", Revue de Métaphysique et de Morale, n. 4, p. 433-445, 1979. . Le Visible et le révelé. Paris: Éditions du Cerf, 2005. 
. God Without Being, translated by Thomas A. Carlson, Chicago: University Chicago Press, 2012.

. Dieu sans l'être. Paris: P.U.F., 2013.

PLATO. Work. Edited with introduction and notes, by John M. Cooper, Indianapolis/Cambridge: Hackett Publishing Company, 1997.

PLATON. Phédon. Présentation et traduction par Monique Dixsaut, Paris: Flammarion, 1991.

- Timée. Présentation et traduction par Luc Brisson, Paris: Flammarion, 2001.

. (2004) La république. Traduction, introduction et notes par Geoorges Leroux, Paris: Flammarion, 2004.

PROCLUS. Commentaire sur la république. Traduction et notes par A. J. Festugière, Paris: Vrin, 1970.

SAÏD, S. Deux Noms de L'Image em Grec Ancien: Idole et Icone, Comptes-rendus des séances de l'Académie des Inscriptions et Belles Lettres, v. 131, n. 2, p. 309-330, 1987.

SEKIMURA, M. Platon et la question des images, Paris: VRIN, 2010.

Data de registro: $12 / 09 / 2016$

Data de aceite: 26/10/2016 